dosage and provides rapid relief. The disadvantage of biguanides is their gastrointestinal side effects, which marred the assessment of earlier clinical trials. If, however, as in this study, a small initial dose is given irrespective of the degree of hyperglycaemia and increased gradually, the side effects are usually mild and transient, and the drug has to be discontinued in only a few, possibly susceptible, patients. The earlier view that the use of biguanides was limited by their side effects therefore seems unjustified. Unlike treatment with the sulphonylureas, treatment with biguanides in therapeutic dosage is not associated with the risk of hypoglycaemia and there is virtual freedom from toxic and hypersensitivity effects.

Treatment with phenformin has been increasingly associated with severe lacticacidosis, especially in the presence of liver or kidney disease, circulatory failure, or other conditions promoting hypoxia, but lacticacidosis may occur in the absence of any of these factors. ${ }^{6}$ Phenformin given in therapeutic doses increases the blood lactate concentration to about $2 \mathrm{mmol} / 1(18.0 \mathrm{mg} / 100$ $\mathrm{ml}),{ }^{i}{ }^{8}$ which under normal circumstances is probably not clinically important. A recent comparative study showed that the rises in concentrations of blood lactate and other glyconeogenic precursors were greater with phenformin than with metformin. It was concluded that these metabolic changes could be accounted for by an inhibitory effect on hepatic glyconeogenesis and were therefore directly related to the lowering action of the biguanides on the blood glucose concentration. The plasma lactate concentration remained normal during glibenclamide treatment, but the serum insulin concentration was higher with the sulphonylurea than with the biguanides. ${ }^{9}$

Metformin, which has been used extensively in Britain and other European countries, is rarely associated with lacticacidosis, possibly because of its different pharmacokinetic properties. When lacticacidosis has occurred there has usually been coexistent renal failure, ${ }^{10}$ and the use of metformin should be avoided not only in this condition but probably also when there is mild renal impairment.

The findings of the University Group Diabetes Program (UGDP) in respect of increased cardiovascular risks with tolbutamide $^{11}$ and phenformin, ${ }^{12}$ although the subject of considerable criticism on the grounds of study design ${ }^{13}$ and analysis, ${ }^{14}$ are nevertheless disturbing. Most of the patients recruited were only mildly hyperglycaemic, asymptomatic, and obese with an average body weight of $130^{\prime}$ " correct weight. They were given fixed doses of the oral agents and would usually have been treated by diet alone in Britain. A statement by a "Task force on Phenformin" group from the American Diabetic Association conceded that in more severe cases of maturity-onset diabetes in which diet was unsuccessful and insulin was either refused or could not be used the use of oral agents could be neither promoted nor discouraged by the UGDP study. ${ }^{12}$

Our results indicate that in non-obese, maturity-onset diabetics whose disease cannot be controlled by diet and who require oral treatment, sulphonylureas and biguanides are equally effective. The choice of agent depends on the degree to which the patient is under weight and the severity of symptoms. If these are pronounced, a sulphonylurea is indicated. If the patient is near correct weight, however, particularly if he is apt to gain weight or if there is a risk of hypoglycaemia or hypersensitivity, then biguanide treatment with metformin might be preferable.

We thank Dr Leslie Duncan for encouragement, and Mrs Sadie Dickson and the staff of the diabetic and dietetic department, Royal Infirmary, for their help.

Requests for reprints should be addressed to Dr B F Clarke.

\author{
References \\ ${ }^{1}$ Mehnert, H, and Seitz, W, Münchener medizinische Wochenschrift, 1958, \\ $100,1849$. \\ 2 Bloom, A, et al, Postgraduate Medical fournal, 1964, 40, 654. \\ 3 Clarke, B F, and Duncan, L J P, Lancet, 1965, 1, 1248. \\ 4 Clarke, B F, and Duncan, L J P, Lancet, 1968, 1, 123. \\ 5 Clarke, B F, and Campbell, I W, Lancet, 1975, 1, 246. \\ 6 Fulop, M, and Hoberman, H D, Diabetes, 1976, 25, 292. \\ : Craig, J W, et al, Diabetes, 1960, 9, 186. \\ ${ }^{8}$ Varma, S K, et al, British Medical fournal, 1972, 1, 205. \\ ${ }^{9}$ Nattrass, M, et al, Diabetologia, 1977, 13, 145. \\ 11 Assan, R, et al, Diabetologia, 1977, 13, 211. \\ 11 University Group Diabetes Program, Diabetes, 1970, 19, suppl No 2, p 747. \\ 1.2 University Group Diabetes Program, Diabetes, 1975, 24, suppl No 1, p 65. \\ ${ }^{13}$ Seltzer, H S, Diabetes, 1972, 21, 976. \\ ${ }^{14}$ Schor, S S, American fournal of Medicine, 1973, 55, 727.
}

\title{
New classification of stroke: preliminary communication
}

\author{
R CAPILDEO, S HABERMAN， F CLIFFORD ROSE
}

British Medical fournal, 1977, 2, 1578-1580

\section{Summary}

We describe a new method of classifying stroke using a cumulative numbering system. The method is simple and more explicit than currently used classifications, and could be useful for different agencies looking after patients with stroke in hospital or at home.

\footnotetext{
Department of Neurology, Charing Cross Hospital (Fulham), London W6 8RF

$\mathrm{R}$ CAPILDEO, MB, MRCP, senior registrar in neurology

F CLIFFORD ROSE, FRCP, consultant neurologist

Department of Social Science and Humanities, City University, London EC1

S HABERMAN, MA, FIA, lecturer in actuarial science
}

\section{Introduction}

There is no universally accepted definition or classification of stroke. This is surprising, since stroke is the third commonest cause of death in the Western world and the single most important cause of disability. We describe here a new classification and terminology for defining stroke. We shall present a full discussion of definitions and classifications previously used with a detailed analysis of the new classification in a subsequent paper.

\section{Terminology}

A stroke is defined as "an acute disturbance of cerebral function of vascular origin causing disability lasting more than, or death within, 24 hours." This definition differs nowadays from that suggested in the report published in July 1974 by a working group of the Royal College of Physicians." Firstly, "vascular origin" replaces the term "presumed vascular origin." Unless the vascular origin has been established by appropriate investigation, the term "presumed stroke" 
should be used. Secondly, the term "death within 24 hours" is necessary to include those who die from a stroke within this period.

In our experience, the term "cerebrovascular accident" (CVA) is the commonest label attached to patients with stroke. The term lacks diagnostic precision and should be avoided. It even creates confusion -has a patient with a "left" CVA sustained a left hemisphere lesion or a left hemiplegia? The diagnosis, for example, of a "left cerebral infarction and right hemiplegia" leaves no room for doubt. There are two types of stroke-cerebral infarction and cerebral haemorrhage.

Cerebral infarction should replace the terms "cerebral thrombosis" and "cerebral embolus." In the past the incidence of cerebral embolism was underestimated, and it is now thought likely to be responsible for $45 \%$ of all cases of cerebral infarction. ${ }^{2}$ Although angiography may show an occlusion, it is usually impossible to determine whether this is due to an embolus with retrograde spread of thrombus or to a thrombus occurring in a stenosed vessel. The term cerebral infarction covers all thromboembolic disease. About $75 \%$ of all strokes are due to cerebral infarction, the remainder being due to cerebral haemorrhage.

Cerebral haemorrhage follows rupture of either a small blood vessel or microaneurysm, a berry aneurysm, or arteriovenous malformation. Other causes of atraumatic haemorrhage include blood dyscrasias, inflammatory vasculitis, and bleeding into or around a brain tumour. The resulting collection of blood may be localised in the brain to form a haematoma. About $80 \%$ of cases have blood in the cerebrospinal fluid:

Subarachnoid haemorrhage means blood in the subarachnoid space. The term should not be used synonymously with "aneurysm," although in $60 \%$ of cases this is the commonest cause. When an aneurysm ruptures directly into the brain, the clinical picture is the same as that of any other cause of cerebral haemorrhage. ${ }^{5}$ The terminology "cerebral haemorrhage secondary to an intracerebral aneurysm" should then be used.

Transient ischaemic attack is defined as "an acute disturbance of cerebral function of vascular origin causing disability lasting less than 24 hours."

These are the principal categories of cerebrovascular disease.

\section{Standard classification}

The standard classification in general use is that published by the World Health Organisation (WHO) in its Manual of the International Statistical Classification of Diseases, Injuries, and Causes of Death (ISCD). The most recent revision is the 9th, carried out in $1974 .^{\circ}$ This revision changed the rubrics and increased the number of categories for ill-defined cerebrovascular disease $(436,437$, and 438$)$.

Table I shows the frequency distribution of deaths due to cerebrovascular disease in England and Wales for each sex for the years 1972 and 1973, and shows that $40 \%$ of all deaths were in the ill-defined cerebrovascular disease group. There seems to be no advantage in including "occlusion of precerebral arteries" (432) as a separate category. In any mortality-based study, transient ischaemic attacks (435) will not be indicated, as by definition they do not cause death

Each revision may introduce new categories and change existing rubrics, thereby making comparisons impossible between studies using different revisions. Although the WHO classification was introduced chiefly for mortality-based studies, it is used for many other types of statistics-for example, coding of hospital inpatient diagnoses. Our main criticisms of the WHO classification are firstly, that it does not indicate the information on which the diagnosis is based, and when the diagnosis is uncertain it does not indicate the degree of doubt; and secondly, because of its rigidity new trends cannot be easily incorporated.

\section{New classification}

The new classification we propose provides information in the following areas: $(a)$ anatomical; $(b)$ pathological; $(c)$ the investigations carried out to confirm $(a)$ and $(b) ;(d)$ associated conditions; $(e)$ disability on admission or $(f)$ on discharge; and $(g)$ outcome (see table II).

For each category we have devised a new shorthand system-the "cumulative numbering system." In each section, 0 is used for unknown information and 9, or serial 9s used to indicate "none." Coding is carried out at the time of discharge from hospital or after death, when all possible sources of information are available. For the patien at home, coding can be carried out at any stage during the illness. The cumulative number obtained in each of the seven categories is unique in that only one possible combination of numbers will arrive at this total-for example, in the anatomical classification (table II $(a)$ ), if the clinician thinks that the patient has a hemisphere lesion and a brain stem lesion, 8 and 2 will be coded, giving a cumulative number of 10 . This number is unique, since no other possible combination will give the number 10 . The "uniqueness" of each cumulative number is the principle of the cumulative numbering system.

TABLE I-Frequency distribution of deaths due to cerebrovascular Disease $(C V D)$ in England and Wales for each sex, 1972 and 1973

\begin{tabular}{|c|c|c|c|c|c|}
\hline \multirow{2}{*}{$\begin{array}{l}\text { Code } \\
\text { No }\end{array}$} & \multirow{2}{*}{ Category* } & \multicolumn{2}{|c|}{1972} & \multicolumn{2}{|c|}{1973} \\
\hline & & M & F & $M$ & $\mathrm{~F}$ \\
\hline $\begin{array}{l}430 \\
431 \\
432 \\
433 \\
434 \\
435 \\
436 \\
437 \\
438\end{array}$ & $\begin{array}{l}\text { Subarachnoid haemorrhage } \\
\text { Cerebral haemorrhage } \\
\text { Occlusion of precerebral arteries } \\
\text { Cerebral thrombosis } \\
\text { Cerebral embolism } \\
\text { Transient cerebral ischaemia } \\
\text { Acute but ill-defined CVD } \\
\text { Generalised ischaemic CVD } \\
\text { Other ill-defined CVD }\end{array}$ & 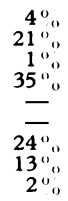 & 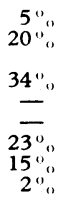 & 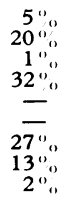 & $\begin{array}{r}5 \% \\
18 \% \\
35 \% \\
=\% \\
26 \% \\
14 \% \\
2 \%\end{array}$ \\
\hline
\end{tabular}

*Categories used are those of 8th Revision of the ISCD. ${ }^{11}$

Percentages corrected to nearest integer.

TABLE II-New classification of stroke using cumulative numbering system

\begin{tabular}{|c|c|c|c|}
\hline $\begin{array}{l}0 \\
1 \\
2 \\
4 \\
8\end{array}$ & $\begin{array}{l}\qquad(a) \text { Anatomical } \\
\text { Unknown } \\
\text { Cerebellum } \\
\text { Brain stem } \\
\text { Right hemisphere } \\
\text { Left hemisphere } \quad \text { Score } \square \square]\end{array}$ & $\begin{array}{r}0 \\
1 \\
2 \\
4 \\
8 \\
16\end{array}$ & $\begin{array}{l}\text { (e) Admission: Disability } \\
\text { Unknown } \\
\text { Speech-Independent } \\
\text { Arm-Useful } \\
\text { Leg-Useful } \\
\text { Speech-Dependent } \\
\text { Arm-Useless }\end{array}$ \\
\hline \begin{tabular}{r|}
0 \\
1 \\
2 \\
4 \\
8 \\
16 \\
32
\end{tabular} & $\begin{array}{l}\qquad(b) \text { Puthological } \\
\text { Unknown } \\
\text { Arteriovenous malformation } \\
\text { Aneurysm } \\
\text { Haematoma/haemorrhage } \\
\text { Intracranial arterial lesion } \\
\text { Extracranial arterial lesion } \\
\text { Infarction } \quad \text { Score } \square \square\end{array}$ & $\begin{array}{r}64 \\
128 \\
256 \\
999\end{array}$ & $\begin{array}{l}\text { Conscious-Drowsy } \\
\text { Unconscious-Reacting } \\
\text { Unconscious-No reaction } \\
\text { None }\end{array}$ \\
\hline $\begin{array}{r}0 \\
1 \\
2 \\
4 \\
8 \\
16 \\
32 \\
64 \\
128 \\
256 \\
999\end{array}$ & $\begin{array}{l}\quad(c) \text { Investigations } \\
\text { Unknown } \\
\text { Electrocardiography } \\
\text { Echo-encephalography } \\
\text { Electroencephalography } \\
\text { Brain scan } \\
\text { Lumbar puncture } \\
\text { Angiography } \\
\text { EMI scan } \\
\text { Neurosurgery } \\
\text { Necropsy } \\
\text { None } \\
\end{array}$ & $\begin{array}{r}0 \\
1 \\
2 \\
4 \\
8 \\
16 \\
32 \\
64 \\
99\end{array}$ & $\begin{array}{l}\text { (f) Discharge: Disability } \\
\text { Unknown } \\
\text { Speech-Independent } \\
\text { Arm-Useful } \\
\text { Leg-Useful } \\
\text { Speech-Dependent } \\
\text { Arm-Useless } \\
\text { Leg-Useless } \\
\text { Dead } \\
\text { None }\end{array}$ \\
\hline $\begin{array}{r}0 \\
1 \\
2 \\
4 \\
8 \\
8 \\
16 \\
32 \\
99\end{array}$ & $\begin{array}{l}\quad(d) \text { Associated conditions } \\
\text { Unknown } \\
\text { Peripheral vascular disease } \\
\text { Diabetes } \\
\text { Previous transient ischaemic } \\
\text { attack } \\
\text { Previous stroke } \\
\text { Ischaemic heart disease } \\
\text { Hypertension } \\
\text { None } \\
\quad \text { Score } \square \square\end{array}$ & $\begin{array}{r}0 \\
1 \\
2 \\
4 \\
8 \\
16 \\
32 \\
64 \\
128 \\
256\end{array}$ & $\begin{array}{l}\quad \text { ( } g \text { ) Outcome } \\
\text { Unknown } \\
\text { At work } \\
\text { At home } \\
\text { Family at home } \\
\text { Outside support-family/friends } \\
\text { Social services support } \\
\text { Other causes for disability } \\
\text { Chair- or bedbound } \\
\text { Institutionalised } \\
\text { Dead } \\
\quad \text { Score } \square \square \square\end{array}$ \\
\hline
\end{tabular}

\section{ANATOMICAL CLASSIFICATION}

Based on the results of examination and appropriate investigations, the probable anatomical site of the lesion can be determined-if not, the diagnosis of "stroke" is doubtful. Coding should be carried out using all sources of information. The category 0 or unknown site should never be used (and is only included for completeness), since this implies that there are no localising signs to establish the probable site of the lesion, and hence the diagnosis of "stroke" should not be made. The basis on which the diagnosis is reached is indicated by the investigations carried out (table II $(c)$ ) and the type of disability produced (table II $(e)$ ).

\section{PATHOLOGICAL CLASSIFICATION}

The pathological diagnosis might be inferred on clinical grounds only, but the investigations used to determine the pathology of the lesion are shown in table II $(b)$. When multiple pathology has been identified, the code numbers for each lesion are added to provide the 
cumulative number, which is then coded-for example, intracranial extracranial vascular occlusions + cerebral infarction $=8+16+32=56$.

To decode, the immediate highest value below the cumulative number is traced and then subtracted from it, continuing until the cumulative number is reduced to zero. A code number of 12 would be decoded thus: 8 is the highest number below it (intracranial arterial lesion) and the remainder will be 4 (haematoma).

\section{INVESTIGATIONS}

A clinical diagnosis without investigations is likely to be inaccurate, as has been well shown by Dalsgaard-Nielsen, ${ }^{7}$ among others. Although it is difficult to assess the relative value of investigations, those in table II (c) are listed in increasing order of diagnostic importance, based on a questionnaire completed by members of the department of neurology, Charing Cross Hospital. The order, however, is not important as each item is readily identified and does not depend on its position in the "league table." Nevertheless, such a league table has an advantage, since higher numbers indicate more investigations carried out, and therefore a greater likelihood of a more accurate diagnosis. The cumulative numbering system makes it possible to identify which tests were actually performed and also instances when none have been carried out.

\section{ASSOCIATED CONDITIONS}

Our classification has a degree of "inbuilt flexibility." If further associated conditions were to be included in later revisions, one more code number would allow three further associated conditions to be included. Nevertheless, previous codings will be valid, as new categories could be easily identified when looking at material coded before or after such a revision.

\section{DISABILITY}

Table II $(e)$ and $(f)$ show a functional type of assessment. The categories used for levels of consciousness are not included in the section on discharge disability $(f)$. A high code number on admission relates to the likely immediate prognosis, hence the high numbers given to levels of consciousness. Clearly, above certain cumulative numbers (256), it is immaterial whether the usefulness or uselessness of the patient's arm or leg is coded, since the immediate prognosis is hopeless. $^{8-10}$

After the patient recovers consciousness, disability can be more accurately assessed. Function is crudely measured in terms of speech and arm and leg function on a three-point scale: independent, dependent, or not affected; useful, useless, or not affected. If speech or a limb is not affected, no category is coded. "Dependent" in the context of speech means a patient can communicate only with his family or speech therapist, but not in an unfamiliar situation or one in which he has to cope alone.

A "useful" limb relates to activities of daily living. An impaired limb can be rendered "useful." A "useful" arm means that the patient's arm has fully recovered or recovered enough to allow him to be independent - that is, feeding, dressing, and toilet without help. A "useful" leg means either complete recovery or the ability to walk, despite disability. Walking may be with or without a walking aid but the patient must be able to manage without other assistance.

\section{OUTCOME}

The categories in table II $(g)$ give an indication of the return to normal life. An extra category of "other causes for disability" is included for patients who appear to have recovered from their stroke (as shown by comparing sections $(e)$ and $(f)$ of the table), but are still dependent on family or social services because of continuing disability, either from another cause-for example, Parkinson's disease or orthopaedic problems, or possibly as the result of repeated strokes. The patient's home background is shown-specifically whether or not they are alone at home, whether they need social services, etc.

\section{THE MASTER CARD}

In the hospital coding is carried out at the same time as the discharge summary. After coding, a master card is filled in ensuring that all columns are completed. Zeros are added to all the empty columns. By looking at the master card correlations become easily apparent. All patients can also be coded for age, sex, dates of hospital admission and discharge (so that duration of stay may be computed), and perhaps race, occupation, and geographical location. The classification of patients is carried out on a punched-card system, having in mind the needs of the different agencies looking after patients with stroke.

\section{Discussion}

We have not tried to analyse in detail all the sections comprised in table II. This will be done in a subsequent paper. We expect to improve the categories with continuing experience. This type of classification is a first step towards combining medical diagnosis, which concentrates on clinical, anatomical, and pathological features, with a "functional" assessment. Social services are more concerned with identifying the type and degree of disability of the patient in the community without needing a medical "label." This new classification can be used by any of the agencies looking after patients with stroke who (1) are admitted to hospital with acute stroke; or (2) are visited at home by the general practitioner (in this case all columns could be completed, although it is unlikely that many investigations will be carried out). Social workers visiting patients at home could use sections $(f)$ and $(g)$ of the table, which will also be useful for follow-up or for monitoring progress-for example, assessment of improvement or increasing dependence.

This approach to classification using explicit coding of the components that constitute a diagnosis allows double-checks to be made, perhaps by computer, so that errors of transcription may be investigated and corrected. The advantages of this proposed classification include: (1) the meaning of the major subdivisions is less open to misinterpretation; (2) use of ill-defined groups such as ISCD rubrics $436-438$ is no longer necessary; (3) the coding rules are simple; (4) in the case of deaths, the certifying physician is encouraged to describe the disease in the same way as in the clinical or hospital records; (5) mortality figures can be related more readily to the results of morbidity studies; (6) the needs of different "users" are explicitly recognised; (7) the proposed classification is more useful than the current ISCD classifications for follow-up studies; and (8) not all users of disease statistics are satisfied by the choice of a single condition with no additional information explaining how that choice was reached. Finally, the methodology can easily be adapted to classify many other neurological diseases, such as head injuries and multiple sclerosis.

We thank Miss Rita Campolini for expert secretarial help. RC gratefully acknowledges financial support from the Harris Trust, and SH from Hambro Life Assurance Ltd.

Requests for reprints should be addressed to Dr R Capildeo.

\section{References}

1 Geriatrics Committee Working Group on Strokes, Report. London, Royal College of Physicians, July 1974.

2 Blackwood, W, et al, Brain, 1969, 92, 897.

3 McKissock, W, Richardson, A, and Walsh, L, Lancet, 1959, 2, 683.

4 Sarner, M, and Rose, F C, fournal of Neurology, Neurosurgery and Psychiatry, 1967, 30, 67.

5 Collier, J, British Medical fournal, 1931, 2, 519.

- Manual of the International Statistical Classification of Diseases, Injuries, and Causes of Death, 9th revision, vol 1. Geneva, World Health Organisation, 1977.

7 Dalsgaard-Nielsen, T, Acta Psychiatrica Scandinavica, 1955, 30, 169.

${ }^{8}$ Rankin, J, Scottish Medical fournal, 1957, 2, 200.

${ }^{9}$ Marquardsen, J, The Natural History of Acute Cerebrovascular Disease. Copenhagen, Munksgaard, 1969.

${ }^{10}$ Oxbury, J M, Greenhall, R D C, and Grainger, K M R, British Medical

Journal, 1975, 3, 125.
${ }^{11}$ Manual of the International Statistical Classification of Diseases, Injuries, and Causes of Death, 8th revision, vol 1. Geneva, World Health Organisation, 1967.

(Accepted 14 October 1977) 